\title{
Why children's health is everyone's business
}

$\mathrm{F}$ rom the BBC programme Playschool some 40 years ago to her current role in the House of Lords as children's champion, Floella Benjamin has consistently delighted her audiences. Delegates at the Royal College of Paediatrics and Child Health (RCPCH) for a conference entitled 'Why children's health is everyone's business' were therefore ready to be impressed by her keynote address.

But no-one was really prepared for the power of Baroness Benjamin's oratory. All present, from dentists to health visitors, from school nurses to paediatricians, were moved by her passion and commitment to the cause of eradicating dental decay in children. Baroness Benjamin took a pledge to continue to fight for improvements in children's oral health because, as she repeatedly said, 'Winners smile - and I want all children to feel like winners'.

The day was part of the RCPCH Insight series which is designed to promote collaboration in child health. It was the first dedicated to dentistry. Hosted by RCPCH at the Museum of London, the day was organised in partnership with the British Society of Paediatric Dentistry (BSPD) and the Office of the Chief Dental Officer (OCDO), England.

At the outset, Baroness Benjamin asked if any of her Playschool babies were in the audience - they were - before moving onto a speech which covered all aspects of dentistry in children. She had been well briefed by a range of dental organisations ensuring her words were authoritative and inclusive.

She said that children's oral health needed to be on the Government's agenda and NHS dentistry needed to be properly funded. 'Poor oral health is a symptom of the increased inequality in this country and it must not happen. It must change. [...] Children with higher levels of disease in primary teeth are at higher risk of disease in secondary teeth.'

Baroness Benjamin discussed the major role of sugar in dental decay as well as the need for the sugar levy. She stressed the crucial role of health visitors and the Dental Check by One campaign. She said it was important to promote the Dental Check by One message wherever possible.

BSPD President Claire Stevens was another upbeat speaker. 'If you want to be part of an unashamedly positive campaign for oral health then BSPD's door is open. Children's oral health is everyone's business and we all have a part to play.'

Referencing Dental Check by One, she continued: 'I say this to you - has there ever been a campaign which has enjoyed so much cross-organisational support?' Claire talked about her week as curator of the NHS Twitter account in October 2017 when she was able to broadcast messages about children's oral health to 23,000 followers. She stressed the importance of reaching out to different audiences in different ways. Claire also talked about the dedicated work to improve children's

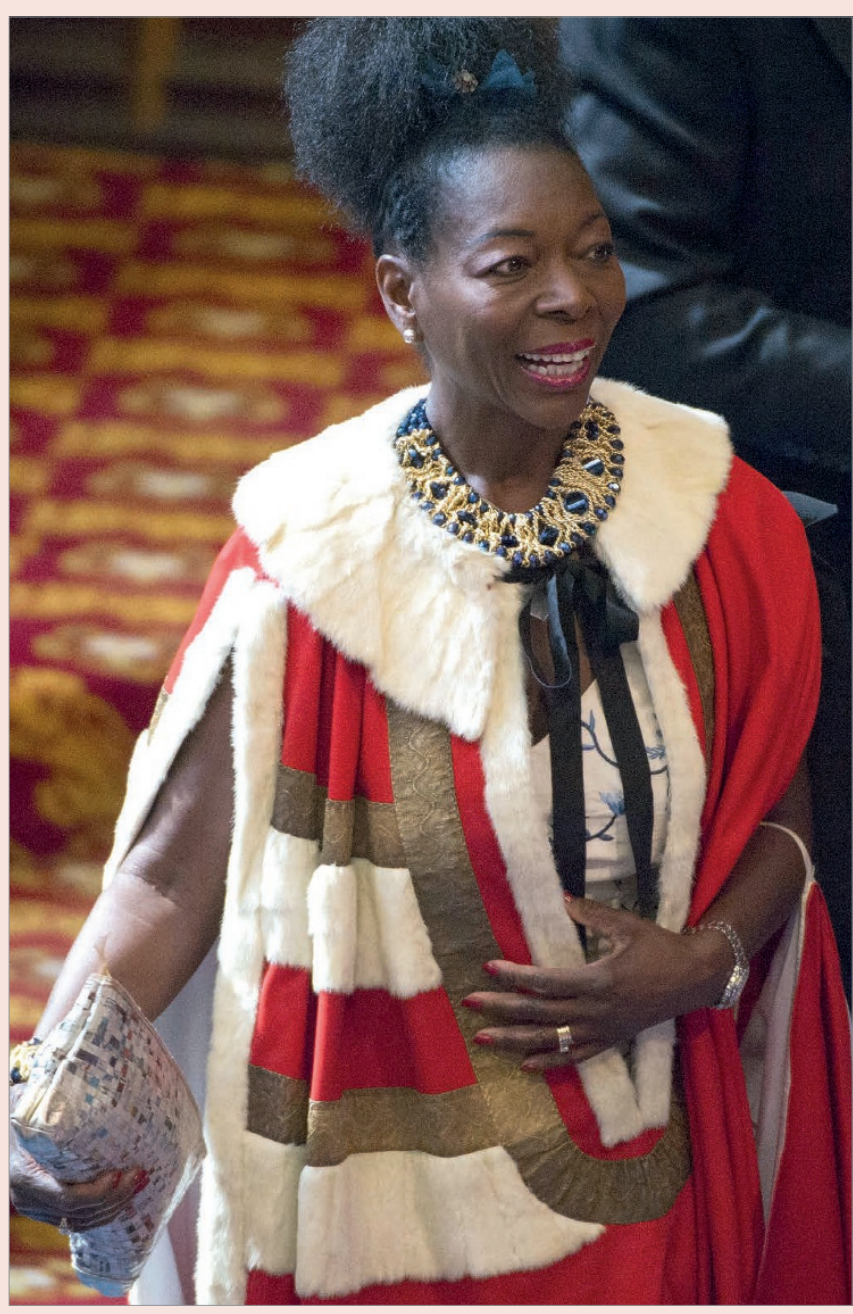

Baroness Floella Benjamin

oral health underway in Greater Manchester, where she works and which now has its own health and social care budget. She acknowledged the role played by GDPs, by Mayor Andy Burnham, by NHS Chief Operating Officer Jon Rouse and by colleagues.

Philippa Bishop, a training programme manager for the Institute of Health Visiting, spoke about how oral health can be incorporated into the working lives of health visitors. A recent survey of 1,000 health visitors found that $100 \%$ agreed that they should be signposting parents to dentists and promoting dental prevention. One of the positive outcomes of the day was the consensus around Philippa's suggestion that health visitors should be commissioned to routinely visit parents at between four to six months because this is the best time to deliver advice on teeth that are erupting - or about to erupt.

Ben Underwood, creator of the Brush DJ app, discussed the need for innovation to help raise awareness of evidence-based 
oral hygiene information and more importantly to achieve behaviour change.

Jenny Harris spoke about safeguarding issues in children's dentistry. She said: 'However you define and measure dental neglect it is clear that it is a common problem worldwide. It is a problem that presents both to general dentists and to specialists, it can present early in childhood or at any time through to adolescence, and it is present at some level in populations that generally enjoy excellent standards of health and wellbeing, and in those that are known to experience high levels of poverty and deprivation'.

Kay Hood, a consultant and specialty lead in paediatric dentistry at the Royal Manchester Children's Hospital, provided a fascinating insight into her working life in her talk 'Oral health needs of complex children'. She stressed how important it is to take the mouth into account in all health assessments, especially children with inherited metabolic disorders who she described as 'a masterclass in health complexity'. She described how medics were preparing to discuss end of life care for a child with a rare condition, mucopolysaccharidosis. He had been distressed and was struggling with his swallowing. There was concern that his overall health was deteriorating. But, a trip to A\&E with a swollen face led to urgent dental treatment under general anaesthetic by Kay's team. Afterwards, the child's health dramatically improved and all talk of end of life care was postponed. Said Kay: 'The impact of dental disease on this complex child's quality of life was very significant indeed. Bad teeth really are bad news'.

Dr Jenny Godson, a Consultant in Dental Public Health and national lead for Oral Health Improvement with Public Health England outlined the many policy documents that had been developed by her team. They have built up an impressive range of evidence-based guidance to support oral health advice to parents.

Richard Watt, a dental epidemiologist from UCL, spoke about inequalities in oral health and the challenges faced by professionals working to support families. He produced one of the most memorable slides of the whole day, two pyramids which show that for every $£ 1$ spent on promoting healthy foods, $£ 500$ is spent by industry on advertising unhealthy foods.

Three eminent figures in the world of dentistry ran the day. Professor Nigel Hunt, the immediate past Dean of the Faculty of Dental Surgery of the Royal College of Surgeons of England (FDS RCS Eng), Chief Dental Officer for England Sara Hurley and Mr Stephen Fayle, Consultant and Senior Clinical lecturer in paediatric dentistry and a member of the Board of FDS RCS Eng.

The final word of this important day should go to Baroness Benjamin: 'I see a light at the end of the tunnel. Child tooth decay is a problem we can and will solve together'.

Supplied by the British Society of Paediatric Dentistry (BSPD) 